\title{
Peningkatan Profesionalisme Pedagogik Mengajar Guru TK, SD, SMP/MTS Melalui Pelatihan Mengajar Gaya Motivator (MGM)
}

\author{
Zulfadewina $^{1}$, Nurmawati ${ }^{1}$, Septi Fitri Meilana ${ }^{1}$ \\ ${ }^{1}$ Universitas Muhammadiyah Prof. DR. HAMKA Jl. Tanah Merdeka, Jakarta Timur, Indonesia \\ Email: Zulfadewina.26@gmail.com
}

\begin{abstract}
Abstrak
Kompetensi pedagogik merupakan kemampuan guru dalam mengelola pembelajaran, sekurang-kurangnya meliputi pemahaman wawasan atau landasan kependidikan, pemahaman terhadap peserta didik, pengembangan kurikulum/silabus, perancangan pembelajaran, pelaksanaan pembelajaran yang mendidik dan dialogis, pemanfaatan teknologi pembelajaran, evaluasi proses dan hasil belajar, dan pengembangan peserta didik untuk mengaktualisasikan berbagai potensi yang dimilikinya. Peningkatan profesionalisme guru sudah sewajarnya dilakukan untuk bisa lebih profesional sehingga tujuan pendidikan nasional dapat tercapai seperti yang tercantum dalam Undang-ndang Guru. Kenyataannya kemauan dan kemampuan guru TK, SD, dan SMP/MTS masih perlu dibina. Tujuan pada peningkatan yang dipaparkan diantaranya berdasarkan permasalahan: 1) Keterbatasan pengetahuan guru untuk pengembangan pembelajaran di sekolah, 2) Standar pendidikan tidak mencukupi, 3) Mengajar selalu menggunakan metode ceramah, dan 4) Minimnya pengetahuan guru mengenai penggunaan media pembelajaran yang tepat dan benar. Melihat berbagai permasalahan tersebut maka diperlukan peningkatan kualitas pendidikan bagi guru khususnya di wilayah Cabang Aisyiyah Ciracas Jakarta Timur. Program Abdimas ini menekankan pada peningkatan profesionalisme pedagogik bagi guru. Tugas guru tidak hanya menyampaikan materi dalam kelas tetapi harus mempunyai kemampuan penggunaan model pembelajaran dan media pembelajaran. Karena saat ini guru dituntut harus berusaha mengembangkan berbagai kemampuan dalam proses pembelajaran. pelatihan mengajar gaya motivator (mgm) ini diharapkan memberikan manfaat besar bagi guru-guru terutama dalam menjalankan perannya sebagai pendidik dan pengurus organisasi Aisyiyah. Materi pelatihan disusun didasarkan atas analisis kebutuhan peserta yang dilaksanakan melalui pelatihan dengan melibatkan guruguru. Hal ini dilakukan untuk mengetahui kondisi dan kebutuhan mereka. Metode pendekatan yang digunakan dalam pengabdian adalah sebagai berikut.1) Pelatiahan, 2) Lokakarya, dan 3) Pembimbingan.
\end{abstract}

Kata Kunci : peningkatan profesionalisme, pedagogik guru, mengajar gaya motivator.

\begin{abstract}
Pedagogic competence is the teacher's abilities to organize in learning process, which are including concept of education; students comprehend; curriculum and syllabus development; learning design; implementation of dialogical learning; utilization of technology; evaluation process and learning outcomes; and learners improvement to actualize their potentials. The community service aim to improve teacher pedagogical competence at Aisyiah Ciracas kindergarten branch of East Jakarta. Teachers pedagogic competence improvement is needed so that the education goals can be achieved as noted in The Law of Teacher number 14 year 2005. To achieve those goals, the community service was providing training for teachers; workshop and mentoring of pedagogic competence especially in assorting learning materials and the appropriate instructional media and elected the right methods of learning process. The training materials are prepared based on teachers need. Based on findings, there were some problems in pedagogical competences of teachers at Aisyiah Ciracas kindergarten branch: 1) teacher's ability to develop learning materials; 2) inadequate standard of education; 3) Using teacher centered model; 4) inappropriate instructional media.
\end{abstract}

Keywords: teacher's professionalism improvement; pedagogic competence; teacher's method 
Format Sitasi: Zulfadewina, Nurmawati \& Meilana, S. F. (2018). Peningkatan Profesionalisme Pedagogik Mengajar Guru TK, SD, SMP/MTS Melalui Pelatihan Mengajar Gaya Motivator (MGM). Jurnal SOLMA, 07(1), 83-89.

Revisi: 27-01-2018; Diterima: 23-03-2018; Diterbitkan: 07-04-2018.

\section{PENDAHULUAN}

Guru adalah aktor utama, selain orang tua dan elemen lainnya. Kesuksesan pendidikan yang dicanangkan. Tanpa keterlibatan aktif guru, pendidikan kosong dari materi, esensi dan substansi. Secanggih apapun kurikulum, visi, misi, dan kekuatan finansial, sepanjang gurunya pasif dan stagnan, maka kualitas pendidikan akan merosot tajam. Sebaliknya, selemah dan sejelek apapun sebuah kurikulum, visi, misi dan kekuatan finansial, jika gurunya inovatif, progresif, dan produktif, maka kualitas pendidikan akan maju pesat. Apalagi jika sistem yang baik ditunjang dengan kualitas guru yang inovatif, maka kualitas lembaga pendidikan semakin dasyat.

Pengelolaan kelas adalah keterampilan guru untuk menciptakan dan memelihara kondisi belajar yang optimal dan mengembalikannya bila terjadi gangguan dalam proses belajar mengajar. Suatu kondisi yang optimal dapat tercapai jika guru, siswa dan sarana pengajaran serta mengedalikannya dalam suasana yang menyenangkan untuk mencapai tujuan pengajaran. Pengelolaan kelas yang efektif merupakan persyaratan mutlak bagi terjadinya proses belajar mengajar.

Mengajar pada prinsipnya membimbing siswa dalam kegiatan belajar mengajar atau mengandung pengertian bahwa mengajar merupakan suatu usaha pengorganisasian lingkungan dalam hubungannya dengan anak didik dan bahan pengajar yang menimbulkan proses belajar. Kompetensi pedagogik merupakan kemampuan guru dalam mengelola pembelajaran, sekurang-kurangnya meliputi pemahaman wawasan atau landasan kependidikan, pemahaman terhadap peserta didik, pengembangan kurikulum/silabus, perancangan pembelajaran, pelaksanaan pembelajaran yang mendidik dan dialogis, pemanfaatan teknologi pembelajaran, evaluasi proses dan hasil belajar, dan pengembangan peserta didik untuk mengaktualisasikan berbagai potensi yang dimilikinya.

Terbentuknya kemampuan dan sikap profesional guru-guru memang tidak mudah, belum tentu terbentuknya kemampuan profesional guru akan sekaligus terbentuk pula sikap profesionalnya, karena banyak faktor yang menentukannya. Meskipun guru telah terdidik di bidang kependidikan, belum tentu secara otomatis terbentuk juga kemampuan 
dan sikap profesional ini. Karena program pendidikan dipelajari kemungkinan tidak atau kurang memberikan penekanan terhadap program pembentukan kemampuan dan sikap profesional.

Peningkatan profesionalisme guru sudah sewajarnya dilakukan, tidak hanya oleh pemerintah tapi dari diri guru itu sendiri juga harus punya kemauan keras untuk bisa lebih profesional sehingga tujuan pendidikan nasional dapat tercapai seperti yang tercantum dalam Undang-undang Guru, dijelaskan bahwa Guru adalah pendidik profesional dengan tugas utama mendidik, mengajar, membimbing, mengarahkan, melatih, menilai dan mengevaluasi peserta didik pada jalur pendidikan formal, serta pada pendidikan dasar dan pendidikan menengah termasuk pendidikan anak usia dini.

Menurut Mulyasa (2007), profesionalisme guru di Indonesia masih sangat rendah, hal tersebut disebabkan karena belum adanya perubahan pola mengajar dan sistem konvensional ke sistem kompetensi, beban kerja guru yang tinggi, dan masih banyak guru yang belum melakukan penelitian tindakan kelas dan masih menggunakan metode ceramah. Atas dasar itulah standar kompetensi dan sertifikasi guru dibentuk agar benarbenar terbentuk guru yang profesional dan mempunyai kompetensi yang sesuai dalam mengajar.

Kompetensi menurut PP No 74 tahun 2008 tentang Guru yaitu merupakan seperangkat pengetahuan, keterampilan, dan perilaku yang harus dimiliki, dikuasai, dan diaktualisasikan oleh guru dalam melaksanakan tugas keprofesionalan. Seorang guru yang berijazah S1 kependidikan belum tentu memperlihatkan kompetensi yang baik, seperti bisa mengajar dengan terampil. Oleh karenanya pemerintah membuat UU No. 14 Tahun 2005 tentang Guru yang menyatakan guru profesional selain memiliki kualifikasi akademik minimal S1, juga harus memiliki empat kompetensi salah satunya adalah kompetensi pedagogik.

Keadaan tersebut menunjukkan bahwa betapa pentingnya seorang guru menanamkan pada diri yakni kompetensi paedagogik. Di wilayah Cabang Aisyiyah Ciracas Jakarta Timur yang dinaungi lima ranting yakni ranting Asiyah Cibubur, Ranting Asiyah Ciracas, Ranting Aisyiyah Susukan, Ranting Aisyiyah kepala dua wetan dan ranting Asisyiyah Rambutan, pengurus Aisyiyah adalah mayoritas sebagai pendidik yakni guru. Dalam penelitian yang dilakukan beberapa tahun yang lalu tentang aktivitas aisyiyah yang didalamnya menganngkut tentang proses mengajar bahwa pengurus Aisyiyah masih 
kurang dalam kekreativitas dalam proses belajar mengajar. Hal ini pengurus Aisyiyah membagi dua posisi disamping sebagai pengurus Aisyiyah juga menjabat sebagai seorang pendidik yakni guru, sehingga untuk mendalami ilmu kompetensi guru sangat minim. Hal ini yang menyebabkan betapa pentingnya memberikan mengajar gaya motivator dan disamping itu agar pengurus Aisyiyah juga dapat tampil didepan sebagai penerus yang memiliki potensi tersendiri dibidang mengajar dan kedepan bisa mendirikan amal usaha Muhammadiyah dibidang pendidikan karena tertanamnya jiwa-jiwa pendidik yang profesional.

\section{MASALAH}

Peningkatan profesionalisme padagogik guru yang lebih baik, untuk itu permasalahan yang dialami oleh Mitra adalah: keterbatasan pengetahuan guru untuk pengembangan pembelajaran di sekolah, standar pendidikan tidak mencukupi, mengajar selalu menggunakan metode ceramah, minimnya pengetahuan guru mengenai penggunaan media pembelajaran yang tepat dan benar secara sederhana sebagai bentuk pengabdian kepada masyarakat. Kegiatan pengabdian ini ditujukan bagi ibu-ibu wilayah Cabang Aisyiyah Ciracas Jakarta Timur. Sehingga setelah pelatihan ini output yang diharapkan dapat meningkatkan kemampuan pedagogik guru.

Tujuan dari pengabdian ini membina guru yang dinaungi lima ranting yakni ranting Asiyah Cibubur, Ranting Asiyah Ciracas, Ranting Aisyiyah Susukan, Ranting Aisyiyah kepala dua wetan dan ranting Asisyiyah Rambutan, meningkatnya kekreativitas dalam proses belajar mengajar.

\section{METODE PELAKSANAAN}

Berdasarkan permasalahan tersebut, maka solusi yang ditawarkan adalah melakukan workshop training mengenai mengajar gaya motivator (MGM). Berikut adalah uraiannya:

a. Persiapan, pada tahap ini peserta disesuaikan dengan minat dan karakteristik yang sudah mereka pahami dan senangi

b. Pelaksanaan, pemateri memberikan gambaran tentang jenis model yang mudah dapat diterapkan dalam pembelajaran, kemudian para guru diberikan pemilihan media yang mereka kuasai, dan melatih kemampuan untuk dapat memanfaatkan daya kreasi dengan menggunakan bahan yang tersedia di lingkungan sekitar. langkah pelaksanaan cocok dalam penerapan gaya motivasi. 
c. Evaluasi, yang dilakukan merupakan umpan balik bagi para guru, sehingga mereka dapat langsung menerapkan mengajar gaya motivator

\section{PEMBAHASAN}

Pada sesi ini dilakukan kegiatan pemaparan materi. Materi yang diberikan kepada peserta adalah bagaimana mengajar ala motivator yang disampaikan oleh Senly Nayoan, $\mathrm{SS}, \mathrm{CHt}, \mathrm{CI}, \mathrm{CNLP}$.
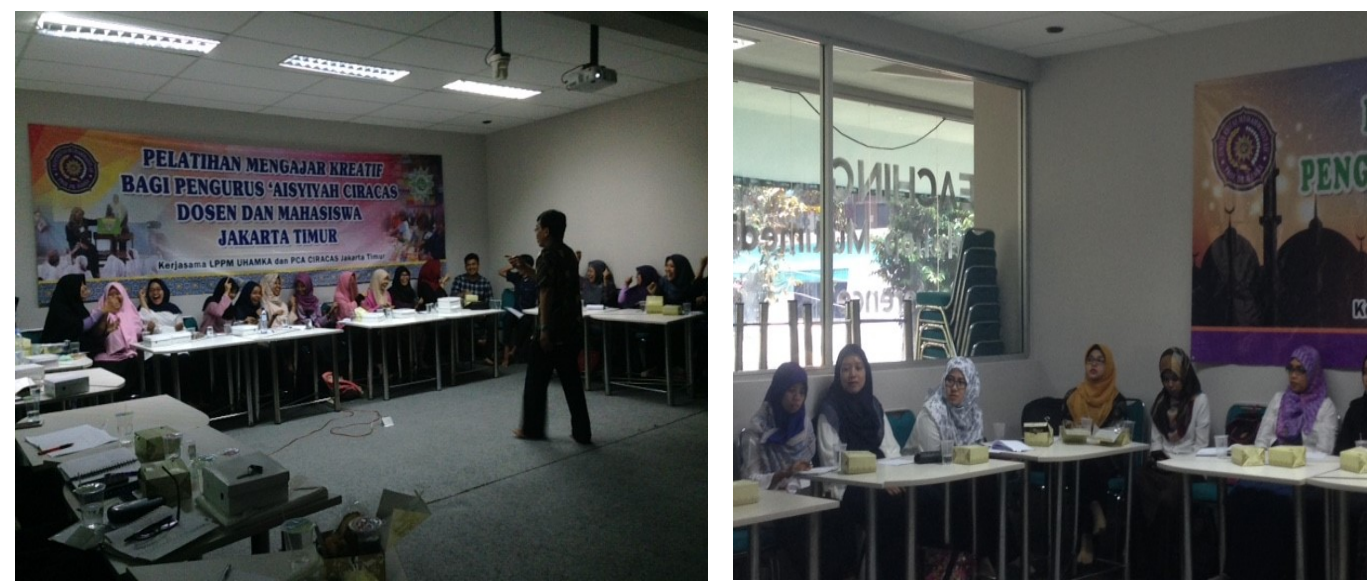

Gambar. Pemaparan materi yang disampaikan oleh Senly Nayoan, SS, CHt, CI, CNLP.

Pemaparan materi ini berlangsung dua jam lamanya. Selama kegiatanberlangsung, ibu-ibu Aisyiyah dan mahasiswa angat antusias. Setelah pemaparan materi selesai, selanjutnya pemateri melakukan praktek dengan cara yang sederhana dengan menyuruh peserta membuat gambar, gambar yang diinstruksikan adalah gambar pertama membuat bebek, dan gambar kedua membuat pemandangan. Gambar yang dibuat tersebut memiliki makna bagaimana kebiasaan yang sering dibuat atau dilakukan. Dikaitkan dengan pelaksanaan di sekolah, seorang guru selalu membuat kebiasaan kepada siswa dari turun temurun tanpa adanya suatu pembaharan. Hal inilah yang sering dilakukan oleh guru-guru yang ada. Tanpa adanya suatu pembaharuan yang dilakukan dalam proses pembelajaran di sekolah, tidak adanya media dan kata-kata hipnotis motivasi yang diberikan kepada siswa.seperti gambar dibawah ini

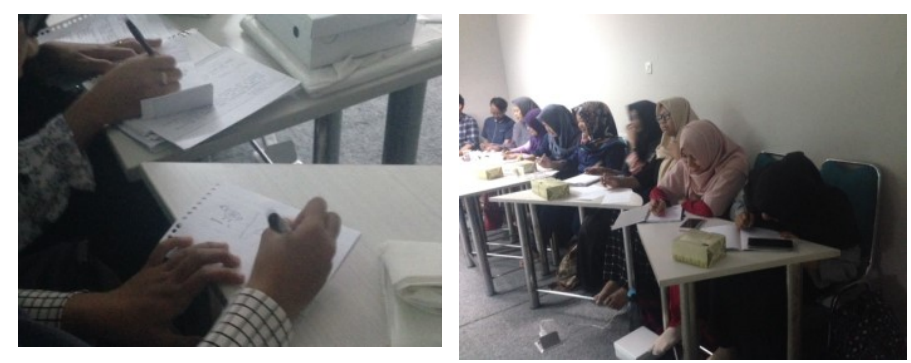

doi: https://doi.org/10.29405/solma.v7i1.663 
Gambar. Peserta sedang membuat gambar dengan merubah mindset

Tahap evaluasi meliputi evaluasi perencanaan dan evaluasi acara. Evaluasi perencanaan dilakukan untuk menilai optimalisasi persiapan kegiatan pengabdian masyarakat. Evaluasi acara dilakukan untuk menilai ketercapaian target pelatihan yang meliputi ketepatan waktu, jumlah peserta, keteraturan acara dan daya tarik peserta.

Berdasarkan evaluasi dari tim pelaksanaan pengabdian dan peserta bahwa hasil pelaksanaan kegiatan pelatihan mengajar gaya motivator adalah sebagai berikut :

Target Tercapai

Jumlah peserta memenuhi lebih dari $60 \%$ target awal bahkan melebihi dari yang direncanakan. Peserta tertib dan antusias dalam mengikuti seluruh rangkaian kegiatan Peserta memberikan respon positif terhadap materi yang diberikan, yaitu dengan pernyataan bahwa mereka mampu mengajar ala motivator dengan memberikan kata-kata positif, pujian, kata bijak dan sebaginya.

Target Belum Tercapai

Pada saat pelaksanaan kegiatan direncanakan, setelah koordinasi dengan pengurus cabang, rencana awal tanggal 20 namun pihak cabang meminta untuk segera dilaksanakan dalam waktu atau minggu yang ditentukan yakni tanggal 12 Mei 2017 dari pengurus cabang karena padatnya jadwal kegiatan dari pengurus cabang Aisyiyah sehingga terkesan mendadak. Monitoring lanjutan pada peserta terkait follow up atas pelatihan yang telah dilakukan yakni dengan melihat dan mendiskusikan hasil mengajar sebelum dan sesudah mengikuti pelatihan tersebut dalam penerapan proses pembelajaran.

Pada bagian pembahasan dijelaskan dan diuraikan tentang peristilahan atau model (untuk jasa, keterampilan baru, dan rekayasa sosial-budaya), dimensi dan spesifikasi (untuk barang/peralatan) yang menjadi luaran atau fokus utama kegiatan yang digunakan sebagai solusi yang diberikan kepada masyarakat, baik langsung maupun tidak langsung. Dicantumkan juga dokumentasi yang relevan dengan jasa atau barang sebagai luaran atau fokus utama kegiatan PkM (foto, tabel, grafik, bagan, gambar dsb.). Kemudian dijelaskan mengenai keunggulan dan kelemahan luaran atau fokus utama kegiatan apabila dilihat kesesuaiannya dengan kondisi masyarakat di lokasi kegiatan PkM. Diakhiri dengan penjelasan mengenai tingkat kesulitan pelaksanaan kegiatan (pelatihan, mediasi dan konsultasi, pendidikan dan advokasi) maupun produksi barang, dan peluangnya. 


\section{KESIMPULAN}

Berdasarkan evaluasi atas perencanaan, pelaksanaan dan evaluasi pada kegiatan pengabdian masyarakat, kesimpulan yang bisa diambil adalah sebagai berikut: Tahap perencanaan dilakukan dengan cukup baik meskipun masih terdapat beberapa kekurangan. Koordinasi LPPM dengan tim pelaksana sudah maksimal dilakukan. Namun koordinasi tim pelaksana dengan mitra masih ada kekurangan terkait waktu pelaksanaan, yang kemudian berimplikasi pada jumlah peserta. Tahap pelaksanaan dengan cukup baik, jumlah peserta sudah memenuhi dari target walaupun sifatnya terkesan mendesak. Dari segi waktu masih belum cukup baik. Tahap evaluasi dilakukan dengan cukup baik sehingga dapat memperbaiki kekurangan yang ada.

\section{UCAPAN TERIMA KASIH}

Terimakasih kepada LPPM (Lembaga Penelitian dan Pengabdian Masyarakat) sebagai pemberi dana kegiatan Pelatihan Mengajar Gaya Motivator bagi Guru di wilayah Cabang Aisyiyah Ciracas, Jakarta.

Terimakasih kepada Pimpinan Cabang Aisyiah (PCA) Cabang Ciracas, sebagai mitra dalam kegitan Pelatihan Mengajar Gaya Motivator bagi Guru di wilayah Cabang Aisyiyah Ciracas, Jakarta

\section{DAFTAR PUSTAKA}

Mulyasa, E., \& Mukhlis. (2007). Standar kompetensi dan sertifikasi guru. Remaja Rosdakarya. Bandung.

Evanita, E. L. (2013). Analisis Kompetensi Pedagogik dan Kesiapan Guru Sekolah Menengah Atas dalam Mendukung Implementasi Kurikulum 2013 (Doctoral dissertation, Universitas Negeri Semarang)

Sardiman, A. M. (2000). Interaksi \& motivasi belajar mengajar. PT RajaGrafindo Persada.

Undang-undang Republik Indonesia Nomor 14 tentang Guru dan Dosen Tahun 2005. (2005). Jakarta

Peraturan Pemerintah Republik Indonesia Nomor 74 tentang Guru Tahun 2008. (2008). Jakarta 